\title{
Epidemio-Clinical Approach and Prognosis of Teenage Delivery in the Commune VI Du District of Bamako in Mali
}

\author{
Soumana Oumar Traoré ${ }^{1,2 *}$, Cheickna Sylla3 ${ }^{3}$ Alou Samaké4, Saleck Doumbia², Saudatou Tall2, \\ Ibrahima Tegueté1,5, Youssouf Traoré1,5, Niani Mounkoro' ${ }^{1,5}$, Mamadou Traoré1,2, \\ Amadou I. Dolo ${ }^{1,3}$
}

${ }^{1}$ Faculty of Medicine and Odontostomatology, University of Sciences, Techniques and Technologies of Bamako, Bamako, Mali ${ }^{2}$ Gynecology-Obstetrics Department, Reference Health Centre of Commune V, Bamako, Mali

${ }^{3}$ Department of Gynecology-Obstetrics, Koutiala Reference Center, Sikasso, Mali

${ }^{4}$ Department of Gynecology-Obstetrics, Reference Health Centre of Commune VI, Bamako, Mali

${ }^{5}$ Department of Gynecology and Obstetrics, Gabriel Touré University Hospital, Bamako, Mali

Email: *traoreoumar69@yahoo.fr

How to cite this paper: Traoré, S.O., Sylla, C., Samaké, A., Doumbia, S., Tall, S., Tegueté, I., Traoré, Y., Mounkoro, N., Traoré, M. and Dolo, A.I. (2020) Epidemio-Clinical Approach and Prognosis of Teenage Delivery in the Commune VI Du District of Bamako in Mali. Open Journal of Obstetrics and Gynecology, 10, 1492-1512. https://doi.org/10.4236/ojog.2020.10100136

Received: September 12, 2020

Accepted: October 27, 2020

Published: October 30, 2020

Copyright $\odot 2020$ by author(s) and Scientific Research Publishing Inc. This work is licensed under the Creative Commons Attribution International License (CC BY 4.0)

http://creativecommons.org/licenses/by/4.0/ Open Access

\begin{abstract}
Objective: To describe the epidemiological aspects, clinical characteristics, aspects of childbirth and to determine the maternal and perinatal prognosis during the delivery of adolescent girls at the reference health centre of commune VI of the district of Bamako in Mali. Materials and Methods: This was a descriptive, cross-sectional, analytical case-control study from January 1 to December 31, 2018, or 12 months with prospective data collection. Results: During the study period from January 01 to December 31, 2018, we recorded 1768 teenage deliveries out of a total of 9012 deliveries, a frequency of $19.61 \%$. The average age of the cases was $17.4 \pm 1$ years. Single adolescent girls accounted for $14.67 \%(\mathrm{OR}=3.05, \mathrm{P}=0.001)$ unintended pregnancies $(11.67 \%$ vs. $2.3 \% ; \mathrm{P}=0.000007 ; \mathrm{OR}=5.52)$, the non-completion of the antenatal consultation $(14.67 \%$ vs. $5.33 \%$; $\mathrm{P}=0.0001$; preterm births $(14.33 \%$ vs. $7.67 \%) ; \mathrm{P}=0.01 ; \mathrm{OR}=2.5)$, anaemia $(7.33 \%$ vs. $3 \% ; \mathrm{P}=0.009$; $\mathrm{OR}=2.01)$, instrumental extractions $(\mathrm{P}=0.00008, \mathrm{OR}=2.87)$, perineal tears $(\mathrm{P}=0.0016$; $\mathrm{OR}=3.05)$, mechanical dystocies $(\mathrm{P}=0.0039)$; low birth weights $(\mathrm{P}=0.039$; $\mathrm{OR}=2.2)$ were found to be significantly higher in adolescent girls than adults. Conclusion: Teenage versus adult births are associated with many more maternal-fetal complications.
\end{abstract}

\section{Keywords}

Childbirth, Teenage Girls, Maternal-Fetal Prognosis 


\section{Introduction}

The word adolescence comes from the Latin verb "adolescere" which means to grow up towards (ad: verse, olescere: grow) [1]. According to the World Health Organization (WHO), the term refers to people aged 10 to 19 . It is a period of physical, psychic and social maturation that extends between childhood and adults [2]. There are one billion adolescents in the world, $85 \%$ of whom live in developing countries [3]. Adolescent girls make up $22 \%$ of the female population in Africa [4]. This population is estimated at 23.1\% in Mali [5]. Adolescence is marked in the daughter by the development and functioning of the reproductive organs. While the occurrence of pregnancy is possible, the adolescent is in a state of psychological imbalance and immaturity of the organs; this poses various problems obstetrical (prematurity, unsafe abortion, dystocia at the time of childbirth...), psychological, and social [2].

However, the definition of teen pregnancy remains unclear, especially with regard to chronological limits. Some authors detain 18 years, others 17 years or 16 years [6] [7] [8] [9] [10].

It is now estimated that one in two girls aged 13 and a half is able in her body to conceive a child.

The age of first sexual intercourse has become more and more early. In France, the average age of first sexual intercourse seems to have stabilized in recent years around 17 and a half years [11]. In Mali, for women aged 25 - 49, the median age at first sexual intercourse is estimated at 17 years [12]. This incredible advance in biological maturation associated with early sexual activity makes it possible to be a parent at an extremely young age.

This age group contributes $14 \%$ to the total fertility of women in Mali [12].

More than 14 million teenage girls give birth each year. Although these births occur in all societies, 12.8 million, or more than $90 \%$, occur in developing countries [13]. 40\% - 50\% of girls have a baby before the age of 18 in Côte d'Ivoire, Liberia, Mali, Cameroon, Bangladesh [13].

For some young mothers, it is a happy event; they are well supported and give birth to a healthy daughter or son. But for millions of others, the pregnancy was not planned; the birth takes place too early and the experience is marked by fear and suffering. Adolescent girls face health risks during pregnancy and birth accounting for $15 \%$ of the global burden of maternal disease, and $13 \%$ of all maternal deaths [13].

The adverse outcomes of these complicated pregnancies and deliveries are essential: preterm birth, neonatal suffering, the birth of a low-weight child and the death of the newborn, without forgetting obstetric fistulas and its consequences on the girl's life [14].

A World Health Organization study on teen pregnancies alone states that age alone may not be the cause, education, social status and use of health facilities are factors involved.

In developing countries, only $53 \%$ of births are cared for by a qualified person. 
Pregnancy among young people not only jeopardizes the health and survival of the child or woman, but also the schooling and professional future of the girl [15]. In Kenya, up to 10,000 girls a year leave school because of their pregnancies [16]. When pregnancy is not desired, it can lead to an abortion, a very limited opportunity in some countries because of its illegality, with its disastrous complications. Of the 19 million illegal abortions that take place each year, 2.2 to 4 million are among teenage girls [17].

In Mali, several studies have been done on teen childbirth. But given the magnitude of the phenomenon and its maternal-fetal complications, this study finds its place.

\section{The Objective}

Was to describe the epidemiological aspects, clinical characteristics, aspects of childbirth and to determine the maternal and perinatal prognosis during the delivery of adolescent girls at the reference health centre of commune VI of the district of Bamako in Mali.

\section{Materials and Methods}

This was a descriptive, cross-sectional, analytical study of type witness cases from January 1 to T December 31, 2018, is 12 months with prospective data collection. The study population: was all parturients admitted to the maternity ward of the reference health center of the as VI during the study period. The scaling was exhaustive. Inclusion criteria: We included in the study all participants meeting the definition of primipara regardless of gestity with a single-fetal pregnancy of at least 28 weeks of gestational age amenorrhea. Cases: These are teenagers between the ages of 10 and 19. Witnesses: These are participants aged 20 and over. We collected a case for a witness. The non-inclusion criteria: for, 1 cases, adolescents who were not primiparous or have multiple pregnancies or a pregnancy of more than 28SAwere not included in the study. For Witnesses: Multiparous or multiple-pregnancy or less than 2 - 8-week amenorrhea patients are not included in the study. The women admitted after childbirth. The variables studied were socio-demographic aspects, clinical characteristics, labour delivery, mode of delivery, caesarean section indications and maternal-fetal prognosis. The participants were subjected to a questionnaire for this purpose. The birthing register; emergency obstetric and neonatal care; Prenatal consultation book (NPC); the partogram and the post partum registry were consulted regularly during our investigation. Data analysis and processing: the counting of questionnaires has been manual. The collected data was captured and analyzed using the Epi Info software, version 3.5.3, the CDC in Atlanta and WHO. The final document was written using Word 2007 and Excel software for tables and graphs. Karl PEARSON's Khi 2 test was the statistical test used for the comparison, significant if $\mathrm{P}=0.05$. The combination test used is Odds Ratio (OR) calculated with $95 \%$ confidence interval. 


\section{Results}

\subsection{Frequency and Socio-Demographic Aspects}

During the study period from January 01 to December 31, 2018, we recorded 1768 teenage deliveries of adolescents out of a total of 9012 deliveries, a frequency of $19.61 \%$. The most represented age group among adolescent girls was 18 - 19 years or 55.67\%; an average age of adolescent girls of $17.4-1.2$ years with extreme ages 14 and 19 years. The average age of controls was 23.19 years - 3.1 years with extreme ages 20 and 40 years. The average age of the spouses was 28.34 - 4.39 years for the cases compared to 34.27 - 5.8 years for the controls. The majority of birth attendants resided in the commune, with a frequency of $82.33 \%$ for adolescent girls and $85 \%$ for controls. The number of girls in school was $39.67 \%$ of adolescent girls who were out of school compared to $30.67 \%$. Of these, $45 \%$ had a primary education level compared to $27 \%$ among controls. In contrast, only $14 \%$ of adolescent girls had a secondary school level compared to $31.67 \%$ of witnesses. Domestic helpers accounted for $13.67 \%$ of adolescent girls compared to $2 \%$ of witnesses. $14.67 \%$ of adolescent girls were single compared to $5.33 \%$ for witnesses. The spouse's profession: Students accounted for $8.33 \%$ of teenage spouses compared to $1.33 \%$ of controls. These epidemiological aspects of parturients are summarized in Table 1.

\subsection{Clinical Features}

Of these, $0.67 \%$ had a history of abortion compared to $8 \%$ of the controls. In our study $13.67 \%$ of adolescent girls used a modern contraceptive method compared to $25.3 \%$. Non-antenatal consultation was more common among adolescents than in controls with the respective frequencies $14.67 \%$ versus $5.33 \%$. The average number of antenatal consultations was 2.7 for adolescent girls compared to 3.7 for controls. Only $36.67 \%$ of adolescent girls had completed at least 4 antenatal consultations compared to $55 \%$ of the witnesses. We also found that failure to perform antenatal counseling was strongly associated with unintended pregnancies, at $72.73 \%$ among adolescents compared to $43.75 \%$ for controls. Adolescent girls are twice as likely to fail to perform antenatal check-ups as controls, at $32.42 \%$ versus $15.85 \%$. Adolescent girls tend to start antenatal consultations later than adults with the average age of pregnancy at the first antenatal consultation at 19.42-5SA compared to 16.4-5.1SA in controls, respectively. Medical and obstetric complications of pregnancy: in our study, the prematurity rate is $7.33 \%$ in adolescents versus $3 \%$ in controls. Anaemia was twice as common among adolescent girls: $14.33 \%$ vs. $7.67 \%$. As for high blood pressure was noted in $14 \%$ among adolescents versus $11 \%$ in controls. Clinical characteristics are summarized in Table 2.

\subsection{Aspects of Childbirth}

\subsubsection{The Process of Childbirth Work}

The reference/evacuation was $38.55 \%$ for cases versus $26 \%$ for witnesses. Direct 
Table 1. The epidemiological aspects of the patients.

\begin{tabular}{|c|c|c|c|c|c|c|c|}
\hline \multirow{2}{*}{ Age } & \multicolumn{2}{|c|}{ Adolescents } & \multicolumn{2}{|c|}{ Witnesses } & \multirow{2}{*}{$\mathbf{P}$} & \multirow{2}{*}{ OR } & \multirow{2}{*}{ IC } \\
\hline & Staff & $\%$ & Staff & $\%$ & & & \\
\hline $14-17$ & 133 & $44.33 \%$ & - & $0 \%$ & - & - & - \\
\hline $18-19$ & 167 & 167 & - & $0 \%$ & - & - & - \\
\hline $20-26$ & - & - & 254 & $84.67 \%$ & - & - & - \\
\hline $27-34$ & - & - & 41 & $13.67 \%$ & - & - & - \\
\hline 35 and over & - & - & 5 & $1.66 \%$ & - & - & - \\
\hline \multicolumn{8}{|l|}{ Residence } \\
\hline Commune VI & 247 & $82.33 \%$ & 255 & $85 \%$ & & & \\
\hline Out of Common VI & 53 & $17.67 \%$ & 45 & $15 \%$ & & & \\
\hline Profession & 41 & $13.67 \%$ & 6 & $2 \%$ & 0.0000011 & 7.75 & {$[3.2-2.65]$} \\
\hline Housekeeper & 16 & $5.33 \%$ & 19 & $6.33 \%$ & 0.6 & 0.8 & {$[0.3-1.7]$} \\
\hline Hairdresser & 8 & $2.67 \%$ & 16 & $5.33 \%$ & 0.09 & 0.48 & {$[0.17-1.2]$} \\
\hline Seamstress & & & 73 & $24.33 \%$ & 0.01 & 1.8 & {$[1.24-2.6]$} \\
\hline Student & 110 & $36.67 \%$ & 124 & $41.33 \%$ & 0.15 & 0.78 & [0.5 - 1.13] \\
\hline Housewife & 107 & $35.67 \%$ & 26 & $8.67 \%$ & 0.21 & 0.67 & {$[0.3-1.3]$} \\
\hline Saleswoman & 18 & $6 \%$ & 32 & $12 \%$ & 0.000000 & 0.0000 & {$[0-0.09]$} \\
\hline Employee & 0 & $0 \%$ & 6 & $2 \%$ & 0.0000011 & 7.75 & [3.2 - 2.65] \\
\hline \multicolumn{8}{|l|}{ Marital status } \\
\hline Bride & 256 & $85.33 \%$ & 284 & $94.67 \%$ & 0.001 & 0.32 & {$[0.16-0.6]$} \\
\hline Single & 44 & $14.67 \%$ & 16 & $5.33 \%$ & 0.001 & 3.05 & {$[1.6-5.9]$} \\
\hline \multicolumn{8}{|l|}{ Spouse's occupation } \\
\hline Driver & 30 & $10 \%$ & 37 & $12.33 \%$ & 0.36 & 0.78 & {$[0.5-1.35]$} \\
\hline Trader & 81 & $27 \%$ & 87 & $29 \%$ & 0.58 & 0.9 & {$[0.62-1.31]$} \\
\hline Student & 25 & $8.33 \%$ & 4 & $1.33 \%$ & 0.00006 & 6.72 & {$[2.28-26.8]$} \\
\hline Mechanic & 34 & $11.33 \%$ & 14 & $4.67 \%$ & 0.004 & 3.61 & {$[1.3-5.38]$} \\
\hline Worker & 50 & $28.07 \%$ & 49 & $28.07 \%$ & 0.91 & 1.02 & {$[0.65-1.6]$} \\
\hline Tailor & 40 & $13.33 \%$ & 40 & $13.33 \%$ & 1 & 1 & {$[0.6-1.64]$} \\
\hline Employee & 40 & $13.3 \%$ & 69 & $23 \%$ & 0.003 & 0.51 & {$[0.32-0.8]$} \\
\hline \multicolumn{8}{|l|}{ Educational level } \\
\hline out of school & 119 & $39.67 \%$ & 92 & $30.67 \%$ & 0.02 & 1.48 & {$[1.05-2.1]$} \\
\hline Primary & 135 & $45 \%$ & 81 & $27 \%$ & 0.000004 & 2.2 & {$[1.5-3.2]$} \\
\hline Secondary & 42 & $14 \%$ & 95 & $31.67 \%$ & 2.510 & 0.35 & {$[1.8-4.4]$} \\
\hline Higher & 4 & $1.33 \%$ & 32 & $10.67 \%$ & 0.0000011 & 0.11 & {$[3.1-34.7]$} \\
\hline
\end{tabular}


Table 2. Clinical characteristics.

\begin{tabular}{|c|c|c|c|c|c|c|c|}
\hline \multirow{2}{*}{ History } & \multicolumn{2}{|c|}{ Adolescents } & \multicolumn{2}{|c|}{ Witnesses } & \multirow{2}{*}{$\mathbf{P}$} & \multirow{2}{*}{ OR } & \multirow{2}{*}{ IC } \\
\hline & Staff & $\%$ & Staff & $\%$ & & & \\
\hline HTA & 5 & $1.67 \%$ & 6 & $2 \%$ & 1 & 0.83 & {$[0.19-3.3]$} \\
\hline Asthma & 10 & $3.33 \%$ & 13 & $4.33 \%$ & 0.52 & 0.76 & {$[0.29-1.9]$} \\
\hline Sickle cell anemia & 2 & $0.67 \%$ & 3 & $1 \%$ & 1 & 0.66 & {$[0.05-5.8]$} \\
\hline $\mathrm{VIH}$ & 3 & $1 \%$ & 1 & $0.33 \%$ & 0.3 & 3 & [0.24 - 159] \\
\hline Diabetes & 1 & $0.33 \%$ & 2 & $0.67 \%$ & 0.56 & 1.2 & {$[0.66-2.4]$} \\
\hline Not & 279 & $93 \%$ & 274 & $91.3 \%$ & 0.4 & 1.2 & {$[0.6-118.7]$} \\
\hline \multicolumn{8}{|l|}{ Contraception } \\
\hline Yes & 41 & $13.67 \%$ & 76 & $25.3 \%$ & 0.0003 & 0.46 & {$[0.2-0.7]$} \\
\hline Not & 259 & $86.33 \%$ & 224 & $74.67 \%$ & 0.0003 & 2.14 & {$[1.3-3.3]$} \\
\hline \multicolumn{8}{|l|}{ Gestity (G) } \\
\hline $\mathrm{G}=1$ & 298 & $99.3 \%$ & 276 & $92 \%$ & 0.00002 & 12.9 & {$[3.1-113]$} \\
\hline$G \geq 2$ & 2 & $0.67 \%$ & 24 & $8 \%$ & 0.00002 & 0.07 & {$[0.008-0.3]$} \\
\hline \multicolumn{8}{|l|}{ Abortion } \\
\hline Not & 298 & $99.3 \%$ & 276 & $92 \%$ & 0.00002 & 12.9 & {$[3.1-113]$} \\
\hline Yes & 2 & $0.67 \%$ & 24 & $8 \%$ & 0.00002 & 0.07 & {$[0.008-0.3]$} \\
\hline \multicolumn{8}{|l|}{ CPN } \\
\hline Yes & 256 & $85.33 \%$ & 284 & $94.67 \%$ & 0.0001 & 0.32 & {$[0.16-0.61]$} \\
\hline Not & 44 & $14.67 \%$ & 16 & $5.33 \%$ & 0.0001 & 3.05 & {$[1.6-5.9]$} \\
\hline \multicolumn{8}{|l|}{ Number of NCCs (N) } \\
\hline Number $=0$ & 44 & $14.67 \%$ & 16 & $5.33 \%$ & 0.0001 & 3.05 & {$[1.6-59]$} \\
\hline Number [1 - 3] & 146 & $48.67 \%$ & 119 & $39.67 \%$ & 0.026 & 1.44 & {$[1.02-2.01]$} \\
\hline Number 4 & 110 & $36.67 \%$ & 165 & $55 \%$ & 0.000006 & 0.47 & {$[0.33-0.6]$} \\
\hline \multicolumn{8}{|l|}{ Reasons for CPNs. } \\
\hline Economic & 7 & $15.91 \%$ & 5 & $31.25 \%$ & 0.19 & 0.42 & {$[0.09-2.04]$} \\
\hline Afraid & 5 & $11.36 \%$ & 4 & $25 \%$ & 0.19 & 0.38 & {$[0.07-2.3]$} \\
\hline Unwanted pregnancy & 32 & $72.73 \%$ & 7 & $43.75 \%$ & 0.037 & 3.42 & {$[0.9-13.4]$} \\
\hline \multicolumn{8}{|l|}{ lieu de CPN } \\
\hline Cabinet/Clinic & 20 & $6.7 \%$ & 31 & $0.3 \%$ & 0.14 & 0.62 & {$[0.33-1.2]$} \\
\hline Community Health Centre & 177 & $69.1 \%$ & 135 & $47.53 \%$ & $0.000 \mathrm{~s}$ & 2.5 & {$[1.7-3.5]$} \\
\hline CSREF & 59 & $3.04 \%$ & 118 & $41.55 \%$ & 0.000004 & 0.42 & {$[0.28-0.62]$} \\
\hline \multicolumn{8}{|l|}{ Auteur CPN } \\
\hline obstetrician nurse & 30 & $11.72 \%$ & 25 & $8.8 \%$ & 0.26 & 1.25 & {$[0.1-2.5]$} \\
\hline Doctor & 26 & $10.16 \%$ & 74 & $26.06 \%$ & 0.000002 & 0.32 & {$[0.18-0.53]$} \\
\hline Midwife & 200 & $78.13 \%$ & 185 & $65.14 \%$ & 0.0008 & 1.9 & {$[1.2-2.8]$} \\
\hline \multicolumn{8}{|l|}{ Prenatal check-up } \\
\hline Yes & 173 & $67.58 \%$ & 239 & $84.15 \%$ & 0.000006 & 0.39 & {$[0.25-0.6]$} \\
\hline Not & 83 & $32.42 \%$ & 45 & $15.85 \%$ & 0.000006 & 2.54 & {$[1.65-3.9]$} \\
\hline
\end{tabular}


admissions were 60.33 per cent for cases and 71.61 per cent for controls. Painful uterine contractions strongly dominate the reason for admission: $91.33 \%$ in cases compared to $91 \%$ in controls. Conjunctiva pallor was more common in adolescent girls, at $8 \%$ than in controls $5.33 \%$. High blood pressure was found at admission in $14 \%$ of cases compared to $11 \%$ of controls. The membranes were ruptured in $34.67 \%$ in adolescents versus $29.33 \%$ in controls. The pelvis was normal in the majority of cases, $89.33 \%$ among adolescents compared to $93.33 \%$ among controls. Fetal heart noises less than 120 beat/mn were detected more in teenage girls $6.33 \%$ than controls $1 \%$. The presentation of the summit was the most represented with frequencies of $92.67 \%$ for cases compared to $91.33 \%$ for witnesses. The admission procedures, the parameters of the mother and the fetus are summarized in Table 3.

\subsubsection{The Mode of Delivery and Caesarean Section Indications}

Natural births accounted for $82.33 \%$ for adolescent girls compared to $84.33 \%$ for controls. We recorded $17.67 \%$ of cases of caesarean delivery in adolescents compared to $15.67 \%$ in controls. Adolescent girls are three times more likely to have a caesarean section for mechanical dystocia, $49.05 \%$ compared to $21.28 \%$ for controls. Vaginal delivery, instrumental extractions and caesarean section indications are summarized in Table 4.

\subsubsection{Maternal and Fetal Prognosis}

The majority of the parturients had given birth without complications, $89.5 \%$ among adolescents compared to $95.26 \%$ among controls. A significant number of perineal tears were observed in adolescent girls, at $6.8 \%$ compared to $2.37 \%$ for controls. We recorded 2 cases of maternal death among adolescent girls or $0.67 \%$ compared to 1 case among controls or $0.34 \%$. Low birth weight (p-lt; 2500 g) was twice as common among adolescents $13.33 \%$ as among controls $6.33 \%$. Apgar's score at the first minute was poor in $10 \%$ of newborns of teenage mothers compared to $9.33 \%$ among controls. Apgar's score was good in $85.33 \%$ of cases compared to $84.67 \%$ for controls. The recorded perinatal deaths were $58.82 \%$ stillborn fresh; $17.65 \%$ stillborn macerated; $23.53 \%$ early neonatal deaths in cases versus $42.11 \%$ of fresh stillbirths; $47.37 \%$ stillborn macerated; $10.52 \%$ of early neonatal deaths in controls. Early maternal, fetal and neonatal complications are summarized in Table 5.

The reasons for the outcome of newborns in neonatology are presented in Figure 1: $22.33 \%$ of newborns from teenage mothers were referred to neonatology compared to $12.67 \%$ of newborns from controls. The reasons for evacuation were essential: neonatal suffering was the most common reference ground, with $38.81 \%$ for cases compared to $31.58 \%$ for controls; hypotrophy with $20.89 \%$ among adolescents versus $26.31 \%$ for controls; prematurity with $32.84 \%$ among adolescent girls versus $23.68 \%$ among controls; fetal macrosomia with $4.48 \%$ in adolescents versus $15.78 \%$ in controls and fetal malformations with $2.98 \%$ in adolescents versus $2.63 \%$ in controls. 
Table 3. Admission procedures and parameters of mother and fetus.

\begin{tabular}{|c|c|c|c|c|c|c|c|}
\hline \multirow{2}{*}{ How to admit } & \multicolumn{2}{|c|}{ Adolescents } & \multicolumn{2}{|c|}{ Witnesses } & \multirow{2}{*}{$\mathbf{P}$} & \multirow{2}{*}{ OR } & \multirow{2}{*}{ IC } \\
\hline & Effectifs & $\%$ & Eff & $\%$ & & & \\
\hline Direct admission & 181 & $60.33 \%$ & 215 & $71.61 \%$ & 0.003 & 0.6 & {$[0.4-0.85]$} \\
\hline Reference/Evacuation & 116 & $38.55 \%$ & 78 & $26 \%$ & 0.0009 & 1.7 & {$[1.2-2.58]$} \\
\hline Hospitalized & 3 & $1 \%$ & 7 & $2.33 \%$ & 0.2 & 0.4 & {$[0.07-1.9]$} \\
\hline \multicolumn{8}{|l|}{ Reason for admission } \\
\hline Uterine contractions & 274 & $91.33 \%$ & 273 & $91 \%$ & 0.89 & 1.04 & {$[0.57-1.9]$} \\
\hline Water losses & 12 & $4 \%$ & 15 & $5 \%$ & 0.55 & 0.79 & {$[0.33-1.84]$} \\
\hline Bleeding & 4 & $1.33 \%$ & 8 & $2.67 \%$ & 0.24 & 0.49 & {$[0.1-1.86]$} \\
\hline \multicolumn{8}{|l|}{ Conjunctiva } \\
\hline Colorful & 276 & $92 \%$ & 276 & $92 \%$ & 0.19 & 0.65 & {$[0.3-1.3]$} \\
\hline Pales & 24 & $8 \%$ & 16 & $5.33 \%$ & 0.19 & 1.54 & {$[0.77-3.2]$} \\
\hline \multicolumn{8}{|l|}{ This } \\
\hline$<14 / 9$ & 258 & $86 \%$ & 267 & $89 \%$ & 0.26 & 0.75 & {$[0.45-1.2]$} \\
\hline$\geq 14 / 9$ & 42 & $14 \%$ & 33 & $11 \%$ & 0.26 & 1.31 & {$[0.78-2.2]$} \\
\hline \multicolumn{8}{|l|}{ State of membranes } \\
\hline Intact & 196 & $65.33 \%$ & 212 & $70.67 \%$ & 0.16 & 0.78 & {$[0.5-1.12]$} \\
\hline Broken & 104 & $34.67 \%$ & 88 & $29.33 \%$ & 0.16 & 1.28 & {$[0.9-1.83]$} \\
\hline \multicolumn{8}{|l|}{ Basin } \\
\hline Limit & 26 & $8.67 \%$ & 19 & $6.33 \%$ & 0.28 & 1.4 & {$[0.73-2.8]$} \\
\hline BGR & 6 & $2 \%$ & 1 & $0.33 \%$ & 0.06 & 6.1 & [0.7 - 281.6] \\
\hline Normal & 268 & $89.33 \%$ & 280 & $93.33 \%$ & 0.08 & 0.56 & {$[0.3-1.1]$} \\
\hline \multicolumn{8}{|l|}{$\mathrm{HU}$} \\
\hline$<36$ & 280 & $93.33 \%$ & 286 & $94.33 \%$ & 0.29 & 0.69 & {$[0.31-1.45]$} \\
\hline$\geq 36$ & $\begin{array}{c}20 \\
6.67 \%\end{array}$ & & $\begin{array}{c}14 \\
4.67 \%\end{array}$ & & 0.29 & 1.45 & {$[0.69-3.2]$} \\
\hline \multicolumn{8}{|l|}{ BDCF } \\
\hline$[120-160]$ & 271 & $90.33 \%$ & 279 & $93 \%$ & 0.24 & 0.7 & {$[0.4-1.3]$} \\
\hline$<120$ & 19 & $6.33 \%$ & 3 & $1 \%$ & 0.0005 & 6.7 & {$[1.9-35.61]$} \\
\hline$>160$ & 5 & $1.67 \%$ & 5 & $1.67 \%$ & 1 & 1 & {$[0.23-4.4]$} \\
\hline Not perceived & 5 & $1.67 \%$ & 13 & $4.33 \%$ & 0.05 & 0.4 & {$[0.1-1.14]$} \\
\hline \multicolumn{8}{|l|}{ LA Color } \\
\hline Clear & 266 & $88.67 \%$ & 271 & $90.33 \%$ & 0.51 & 0.84 & [0.48 - 1.5] \\
\hline Misconial & 34 & $11.33 \%$ & 29 & $9.67 \%$ & 0.51 & 1.2 & {$[0.68-2.1]$} \\
\hline \multicolumn{8}{|l|}{ Presentation } \\
\hline Summit & 272 & $92.67 \%$ & 274 & $91.33 \%$ & 0.65 & 1.2 & {$[1.1-5.1]$} \\
\hline Siege & 15 & $5 \%$ & 21 & $7 \%$ & 0.3 & 0.7 & {$[0.3-1.5]$} \\
\hline Other & 7 & $2.33 \%$ & 5 & $1.67 \%$ & 0.56 & 1.4 & {$[0.4-5.7]$} \\
\hline
\end{tabular}


Table 4. Distribution of parturients by vaginal delivery, instrumental extractions and caesarean section indications.

\begin{tabular}{|c|c|c|c|c|c|c|c|}
\hline \multirow{2}{*}{ Childbirth lane } & \multicolumn{2}{|c|}{ Adolescents } & \multicolumn{2}{|c|}{ Witnesses } & \multirow{2}{*}{$\mathbf{P}$} & \multirow{2}{*}{ OR } & \multirow{2}{*}{ IC } \\
\hline & Eff & $\%$ & Eff & $\%$ & & & \\
\hline Low track & 247 & $82.33 \%$ & 253 & $84.33 \%$ & 0.5 & 0.87 & {$[0.6-1.4]$} \\
\hline Caesarean section & 53 & $17.67 \%$ & 47 & $15.67 \%$ & 0.5 & 1.15 & {$[0.7-1.8]$} \\
\hline \multicolumn{8}{|l|}{ Low track } \\
\hline Sucker & 51 & $20.65 \%$ & 21 & $8.3 \%$ & 0.00008 & 2.87 & {$[1.6-5.2]$} \\
\hline Normal & 196 & $79.35 \%$ & 232 & $91.7 \%$ & 0.00008 & 0.35 & {$[0.19-0.6]$} \\
\hline \multicolumn{8}{|l|}{ Indication } \\
\hline Mechanical dystocia & 26 & $49.05 \%$ & 10 & $21.28 \%$ & 0.0039 & & \\
\hline Basin generally shrunk & 6 & $11.32 \%$ & 1 & $2.13 \%$ & & & \\
\hline Failed work probation & 5 & $9.43 \%$ & 4 & $8.5 \%$ & & & \\
\hline Disproportion foeto-pelvic & 3 & $5.66 \%$ & 1 & $2.13 \%$ & & & \\
\hline Vicious presentation & 5 & $9.43 \%$ & 2 & $4.26 \%$ & & & \\
\hline Pre-uterine rupture syndrome & 2 & $3.77 \%$ & - & - & & & \\
\hline Lack of commitment & 5 & $9.43 \%$ & 2 & $4.26 \%$ & & & \\
\hline Dynamic dystocia & 9 & $16.98 \%$ & 13 & $27.66 \%$ & 0.19 & & \\
\hline Stationary dilation & 5 & $9.43 \%$ & 7 & $14.89 \%$ & & & \\
\hline Trigger failure & 4 & $7.55 \%$ & 6 & $12.77 \%$ & & & \\
\hline Seat/Primipare & 4 & $7.55 \%$ & 6 & $12.77 \%$ & 0.39 & & \\
\hline Acute fetal suffering & 9 & $16.98 \%$ & 11 & $23.4 \%$ & 0.42 & & \\
\hline Funicular anomaly & 7 & $13.20 \%$ & 8 & $17.02 \%$ & & & \\
\hline Hretro-placental ematoma & 2 & $3.77 \%$ & 3 & $6.38 \%$ & & & \\
\hline Placenta prævia & 2 & $3.77 \%$ & 3 & $6.38 \%$ & 0.55 & & \\
\hline Severe pre-eclampsia & 3 & $5.66 \%$ & 4 & $8.5 \%$ & 0.39 & & \\
\hline
\end{tabular}

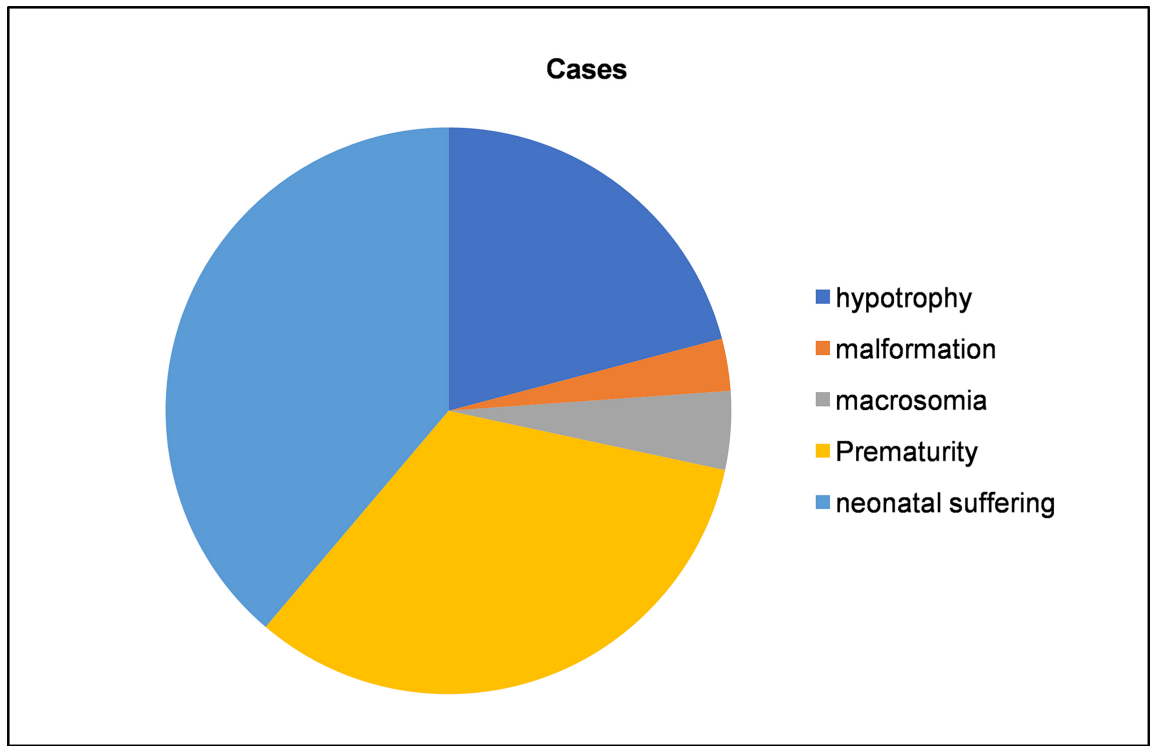

Figure 1. Distribution of newborns based on the reasons for their paediatric references. 
Table 5. Early maternal, fetal and neonatal complications.

\begin{tabular}{|c|c|c|c|c|c|c|c|}
\hline \multirow{2}{*}{ Complications } & \multicolumn{2}{|c|}{ Adolescents } & \multicolumn{2}{|c|}{ Witnesses } & \multirow{2}{*}{$\mathbf{P}$} & \multirow{2}{*}{ OR } & \multirow{2}{*}{ IC } \\
\hline & Eff & $\%$ & Eff & $\%$ & & & \\
\hline Yes & 15 & $5 \%$ & 10 & $4.17 \%$ & 0.31 & 1.5 & {$[0.63-3.9]$} \\
\hline Not & 285 & $95 \%$ & 290 & $95.83 \%$ & 0.31 & 0.66 & {$[0.26-1.6]$} \\
\hline \multicolumn{8}{|l|}{ Complications } \\
\hline Perineal tear & 17 & $6.8 \%$ & 6 & $2.37 \%$ & 0.016 & 3.05 & {$[1.2-9.6]$} \\
\hline Cervical tear & 5 & $2.02 \%$ & 5 & $1.98 \%$ & 0.96 & 1.02 & {$[0.2-4.5]$} \\
\hline Vulvar hematoma & 4 & $1.62 \%$ & 1 & $0.4 \%$ & 0.16 & 4.1 & [0.4 - 205.1] \\
\hline No & 221 & $89.5 \%$ & 241 & $95.26 \%$ & 0.015 & 0.4 & {$[0.19-0.8]$} \\
\hline \multicolumn{8}{|l|}{ Maternal death } \\
\hline Yes & 2 & $0.67 \%$ & 1 & $0.34 \%$ & 0.58 & 1.95 & {$[0.1-115.7]$} \\
\hline Not & 298 & $99.33 \%$ & 299 & $99.66 \%$ & 0.58 & 0.49 & {$[0.008-9.6]$} \\
\hline \multicolumn{8}{|l|}{ Apgar lere Minute } \\
\hline$[0-3]$ & 14 & $4.67 \%$ & 18 & $6 \%$ & 0.47 & 0.77 & [0.35 - 1.67] \\
\hline$[4-7]$ & 30 & $10 \%$ & 28 & $9.33 \%$ & 0.78 & 1.08 & {$[0.6-1.9]$} \\
\hline$[8-10]$ & 256 & $85.33 \%$ & 254 & $84.67 \%$ & 0.82 & 1.05 & {$[0.66-1.7]$} \\
\hline \multicolumn{8}{|l|}{ Apgar } \\
\hline 0 & 13 & $4.33 \%$ & 17 & $5.67 \%$ & 0.45 & 0.75 & {$[0.3-1.68]$} \\
\hline$[0-3]$ & 4 & $1.33 \%$ & 2 & $0.67 \%$ & 0.41 & 2.01 & {$[0.2-22.3]$} \\
\hline$[4-7]$ & 5 & $1.67 \%$ & 2 & $0.67 \%$ & 0.25 & 2.5 & [0.41 - 26.7] \\
\hline$[8-10]$ & 278 & $92.67 \%$ & 278 & $93 \%$ & 0.87 & 0.95 & {$[0.49-1.86]$} \\
\hline \multicolumn{8}{|l|}{ Weight (g) } \\
\hline$<2500$ & 40 & $13.33 \%$ & 19 & $6.33 \%$ & 0.0039 & 2.2 & {$[1.25-4.3]$} \\
\hline [2500 - 3999] & 257 & $85.67 \%$ & 275 & $91.67 \%$ & 0.021 & 0.54 & {$[0.31-0.94]$} \\
\hline$\geq 4000$ & 3 & $1 \%$ & 6 & $2 \%$ & 0.31 & 0.5 & {$[0.08-2.35]$} \\
\hline \multicolumn{8}{|l|}{ Referred to paediatrics } \\
\hline Yes & 67 & $22.33 \%$ & 38 & $12.67 \%$ & 0.002 & 1.98 & {$[1.3-3.15]$} \\
\hline Not & 233 & $77.67 \%$ & 262 & $87.33 \%$ & 0.002 & 0.50 & {$[0.32-0.79]$} \\
\hline \multicolumn{8}{|l|}{ Type of death } \\
\hline Early neonatal death & 4 & $23.53 \%$ & 2 & $10.52 \%$ & 0.29 & 2.6 & {$[0.31-32.3]$} \\
\hline Fresh stillborn & 10 & $58.82 \%$ & 8 & $42.11 \%$ & 0.32 & 1.96 & {$[0.4-9.08]$} \\
\hline Stillborn macerated & 3 & $17.65 \%$ & 9 & $47.37 \%$ & 0.05 & 0.23 & {$[0.03-1.3]$} \\
\hline
\end{tabular}

\subsubsection{Pathologies of Diaper Suites}

In our study postpartum anaemia, postpartum eclampsia, endometritis were found to be more common in adolescent girls than in controls: $3.3 \%$ vs. $2 \%$, $1.33 \%$ vs. $1 \%, 2.67 \%$ vs. $0.67 \%$ respectively. These pathologies of diaper sequences are summarized in Figure 2. 


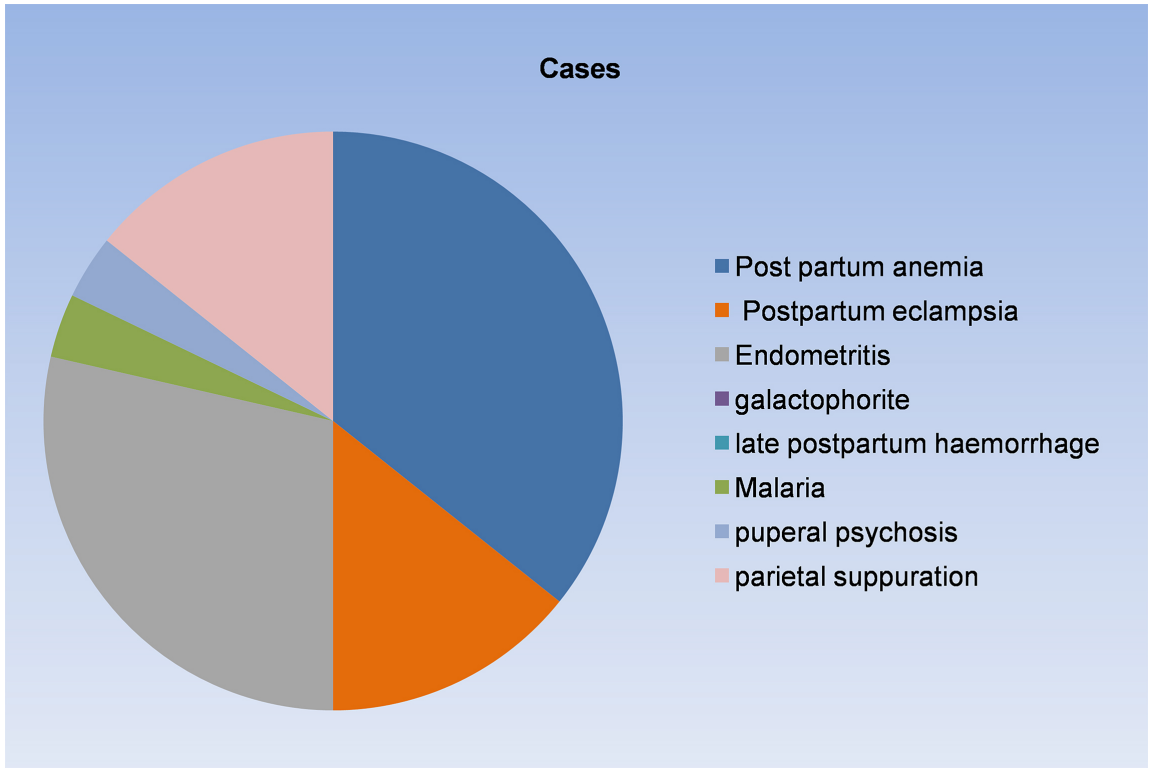

Figure 2. Distribution of parturients according to complications of diaper suites.

\section{Discussion}

\subsection{The Frequency of Teen Delivery}

In the literature, studies on adolescence pose problems, comparisons are difficult because the chronological limits of this segment of the population are not precisely defined. Some authors take an upper age of 18, others 17 years, and 16 years for some [6] [7] [8] [9]. We took the 10 - 19 age group recommended by WHO. In our series, this frequency was $19.61 \%$ superimposed on previous studies in Mali. Dembélé F. [18] in 2015, Dembélé S. [19] in 2012, Sanogo M. [20] in 2009, Yattasaye A. [4] in 1998 had found a teenage delivery frequency of 19.2\%; 21.72\%; 12.11\%; 18.14\% respectively. According to LEKE J.F.R. [21] in 1995, the incidence of teen pregnancy in black Africa ranged from 5 to $20 \%$. The teen birth rate is much lower in developed countries such as France with $0.6 \%$, the USA with 5.6\%, Great Britain with 2.6\% [22] in 2010. The high frequency of early marriages in our countries; the low level of education; the low use of contraception among adolescent girls; cultural and religious factors are factors that may explain this difference between the frequencies observed in Africa and elsewhere in the world.

\subsection{Socio-Demographic Aspects}

In our study, the age group most represented among adolescent girls was 18 - 19 years old with $55.67 \%$ with an average age of 17 years - 1.2 years. In Mali, Dembélé F. [18] found that $55.73 \%$ of adolescent girls were between 18 - 19 years of age. On the other hand Sanogo M. [20] reported that the most represented age group was 16 - 17 years with 50.3\%. Dembélé S. [19] in its study found that $80 \%$ of adolescent girls were under the age of 18 with an average age of 17 . We have not reported births among adolescent girls under the age of 14 . We believe that 
very young adolescent girls under the age of 15 were most often spared the scarcity of sexual activity and/or generally anovulatory cycles in this age group. Geographical accessibility, the quality of services, trust in the sick-provider relationship is important in the use of a structure and medical care. Thus, the majority of the birth attendants were residents of the study commune, a frequency of $82.33 \%$ for adolescent girls and $85 \%$ for controls. Educational attainment: Studies of adolescent fertility affirmed the importance of education as a limiting factor in early fertility [23] [24]. In our study, we found that $39.67 \%$ of adolescent girls were out of school compared to $30.67 \%$ of controls (P-0.02; OR-1.48). Dembélé S. [19] reported that $69.8 \%$ of adolescent girls compared to $90.3 \%$ of controls were out of school. Coulibaly B. [25] and Yattasaye A. [4] reported $91.21 \%$ and $29.3 \%$ of out-of-school adolescent girls respectively. Our low rate of non-schooling compared to Dembélé S. [19] is due to the fact that our study is conducted in urban areas unlike that of Dembélé S. [19] carried out in rural areas. There is a clear difference between the rates of adolescent girls not enrolling in developed and developing countries. In Italy, the rate of non-enrolment in this age group is $1 \%$, in Israel the rate is $4 \%$. Schooling: Adolescent girls who were in school were twice as likely to be in the control group. Female participants with a primary education level were the most numerous among adolescent girls $45 \%$ versus $27 \%$ among controls $(\mathrm{P}=0.000004$; $\mathrm{OR}=2.2)$. On the other hand, only $14 \%$ of adolescent girls had a secondary school level compared to $31.67 \%$ of the controls $\left(\mathrm{p}=2.5 \times 10^{-7}\right.$; OR $\left.=2.85\right)$. Teenage girls, once pregnant, are removed from school or drop out because of pregnancy or marriage. Dembélé S. [19] in 2012 found that $18.9 \%$ and $11.3 \%$ of the participants who had attended primary and secondary school respectively were adolescent girls. And Drabo A. [26] in 2015 reported $34.5 \%$ of adolescent girls with a primary education level compared to $5 \%$ of controls. Occupation: Domestic helpers accounted for $13.67 \%$ of adolescent girls compared to $2 \%$ of controls $(\mathrm{P}=0.0000011, \mathrm{OR}=$ 7.75). Drabo A. [26] reported that $13.1 \%$ of adolescent girls compared to $1.5 \%$ of witnesses were housekeepers. Sanogo M. [20] had found 35\% of domestic helpers among teenage girls. Similarly, in our study, students accounted for $36.67 \%$ of adolescent girls compared to $24.33 \%$ of controls (p-0.01 and OR-1.8). Dembélé F. [18] found that students accounted for $26.57 \%$ of adolescent girls compared to $8.04 \%$ of witnesses. This high frequency of students among adolescent girls is explained by the lack of sex education in the school curriculum and the media masses (television, internet, etc.). Marital styling: Child marriage is defined as any marriage in which a person is under the age of eighteen and is a widespread practice in all regions of the world. This harmful traditional practice not only violates the human rights of girls and young women, but also threatens their health and well-being [27] [28]. The place of marital status in pregnancies and childbirth has been the subject of much study [29] [30]. In our series $85.33 \%$ of teenage girls were married compared to $94.67 \%$ of the witnesses (P-0.001). Dembélé F. [18] in 2015, Dembélé S. [19] in 2012, Drabo A. [26] in 2015, and 
Traoré F. [31] in 2002 found 86.98\%, 79.2\%, 73.6\%, 62\% of teenage girls married in their studies, respectively. In our series $14.67 \%$ of adolescent girls were single compared to $5.33 \%$ for the witnesses $(P=0.001$, OR $=3.05)$. Dembélé $S$. [19] and Dembélé F. [18] reported $20.8 \%$ and $13.02 \%$ of single adolescent girls respectively. P.H. Boisselier in France [32] in 1985 in the French journal of obstetrics and biological gynecology and reproductive biology, found 75\%of Frenchteenagers single compared to $15 \%$ of African adolescents single. This high rate of married teenage girls could be explained by early marriage in our country. The profession of the spouse: Women during their pregnancies are mainly supported by their spouses especially with regard to the financial means and this depends not only on their wishes but on their activities. Teenage girls are more likely to become pregnant with inactive spouses [26]. In our study, students accounted for $8.33 \%$ of teenage spouses compared to $1.33 \%$ of controls $(\mathrm{P}=$ 0.00006 , OR $=6.72$ ). Drabo A. [26] found $31.8 \%$ of students as teenage spouses compared to $26.4 \%$ among controls.

\subsection{The Clinical Aspects}

$99.3 \%$ of adolescent girls were at first pregnancy compared to $92 \%$ of controls ( $\mathrm{P}$ $=0.00002$ ). Those with a history of abortion were $0.67 \%$ compared to $8 \%$ for controls. Dembélé F. [18] and Nekam F. [32] in 1995 had found a history of abortions, in $4.69 \%$ and $1.2 \%$, respectively. Numerous studies have shown low contraceptive use among adolescent girls and are considered a determining factor in the onset of pregnancy. In Hamada's series [33] in Rabat, Morocco in the Journal of Obstetric Gynecology and Reproductive Biology in 2004, 22.4\% of adolescent girls used at least one contraceptive method compared to $20 \%$ in sub-Saharan Africa, 5\% in India and Pakistan, 40\% in Indonesia and Thailand, $30 \%$ to $53 \%$ in Latin American and Caribbean countries [34], 58\% in France and $82 \%$ in Denmark [35]. In our study $13.67 \%$ of adolescent girls used a modern contraceptive method compared to $25.3 \%$ in controls $(\mathrm{P}=0.0003$; $\mathrm{OR}=2.14)$. As for Drabo A. [26], contraceptive use was $9.1 \%$ among adolescents versus $25 \%$ among controls.

Prenatal counseling: The purpose of prenatal consultation is to safeguard a woman's health during pregnancy, to allow her to give birth to a healthy child and to teach her the care of the newborn [21]. The failure to perform this antenatal consultation was more common in adolescent girls than in controls with the respective frequencies $14.67 \%$ versus $5.33 \%$. The difference was statistically significant with a 3.05-fold increase in the risk of a pregnant adolescent not performing this antenatal consultation $(\mathrm{P}=0.0001, \mathrm{OR}=3.05)$. The average number of antenatal consultations was 2.7 for adolescent girls compared to 3.7 for controls. Only $36.67 \%$ of adolescent girls had completed at least 4 antenatal consultations compared to $55 \%$ of the witnesses. Drabo A. [26], reported $6.8 \%$ of unsured teenage pregnancies compared to $2.8 \%$ among adult controls. Diallo A. [36] and Dembélé S. [19] had found higher rates of unsured pregnancies with 
$30.02 \%$ and $58 \%$ respectively among adolescent girls compared to $15.02 \%$ and $16 \%$ among controls. Traoré B. [37] reported $23.7 \%$ of adolescent girls who did not have antenatal care. We also found that failure to perform antenatal counseling was strongly associated with unintended pregnancies, at $72.73 \%$ among adolescent girls compared to $43.75 \%$ in controls with a statistically significant difference $(\mathrm{P}=0.037$; $\mathrm{OR}=3.42)$. Drabo A. [26] found in her study that women with unintended pregnancies had performed less antenatal care $(\mathrm{P}=0.081, \mathrm{OR}=$ 2.87). An unwanted pregnancy is a disgrace to the girl and her family in our society. The family is not concerned with pregnancy monitoring and often the procreator who needs to care for it is not known. In addition to limited financial resources. For example, these adolescent girls are twice as likely to fail to perform antenatal check-ups as controls, at $32.42 \%$ versus $15.85 \%$ with a statistically significant difference $(\mathrm{P}=0.000006$; $\mathrm{OR}=2.54)$. Adolescent girls tend to start antenatal consultations later than adults with the average age of pregnancy at the first antenatal consultation at 19.42-5SA compared to 16.4-5.1SA in controls, respectively. According to $\mathrm{WHO}$, in developing countries, young pregnant women often come late for antenatal consultations (in the second or third trimester of pregnancy) or do not even show up for antenatal care. The reasons given for this apathy towards antenatal care services include: ignorance of the importance of antenatal care (especially among non-registered), lack of family or social support, poverty, unpleasant remarks from health workers to unmarried adolescents who are pregnant [38]. Fear of HIV testing [39].

In the literature, numerous studies have shown the high frequency of anaemia in adolescent girls especially in developing countries where half of adolescent girls are anemic. The latter is favoured by intestinal parasitic infections, malaria, nutritional deficiency of iron and folic acid. Teenage mothers with iron deficiency anemia are more likely to give birth before term [2] [13] [19]. In our study, the prematurity rate was $7.33 \%$ among adolescents compared to $3 \%$ among controls with a 2.5 -fold increased risk of preterm birth $(\mathrm{P}=0.01$; $\mathrm{OR}=$ 2.5). According to Boisselier [32], the rate of preterm birth among adolescent girls is $11.5 \%$ while it reaches $30 \%$ according to Suraiya [40]. Anaemia was twice as common among adolescent girls: $14.33 \%$ vs. $7.67 \%$ with a 2.01 -fold increase in risk for adolescent girls $(\mathrm{P}=0.009$; $\mathrm{OR}=2.01)$. This rate is comparable to the literature on which the rate of adolescent anaemia ranges from 12.5 to $25 \%$ [41] [42] [43]. We found no statistically significant difference in high blood pressure, $14 \%$ in adolescent girls versus $11 \%$ in controls with $(P=0.26)$; the rate of high blood pressure in adolescent girls varies between $10 \%$ and $17.5 \%$ [41]-[46]. The rate of malaria among adolescent girls in our study was $11.67 \%$ comparable to that of the literature which is estimated at $15 \%$ [47].

\subsection{Aspects of Childbirth}

\subsubsection{How the Labour Work Unfolded}

Referral/evacuated participants were $38.55 \%$ for cases versus $26 \%$ for controls. 
Adolescent girls were 1.74 times more likely to be referred/evacuated than controls $(\mathrm{P}=0.0009 ; \mathrm{OR}=1.74)$. Dembélé $\mathrm{F}$. [18] found that $22.92 \%$ of adolescent girls versus $8.29 \%$ of witnesses were admitted according to the reference/evacuation mode. Painful uterine contractions were the reason for admission in $91.33 \%$ in cases versus $91 \%$ in controls. The absence of iron and folic acid supplementation due to the failure to perform antenatal consultation explains the frequency of conjunctival pallor higher in adolescents at $8 \%$ than in controls $5.33 \%(\mathrm{P}=0.19)$. Our rate is higher than Drabo A. [26] which had regained pallor in $6.3 \%$ of adolescent girls compared to $1.8 \%$ among controls. High blood pressure was found at admission in $14 \%$ of cases compared to $11 \%(\mathrm{P}=0.26, \mathrm{OR}$ $=1.31$ ). Drabo A. [26] had found high blood pressure at admission in $2.5 \%$ of adolescent girls versus $2.4 \%$ in controls. Diallo A. [36] in his study reports that $24.22 \%$ of adolescent girls had high blood pressure at admission. Prolonged work with ruptures of membranes is common in our context. Adolescent girls were 1.28 times more likely to have ruptured membranes at admission. Most often, this rupture of membranes is made at the level of community health centers. They were broken in $34.67 \%$ among adolescent girls compared to $29.33 \%$ among controls with $(\mathrm{P}=0.16$; $\mathrm{OR}=1.28)$. Drabo A. [26] reported that membranes were ruptured at admission in $19.1 \%$ of adolescent girls compared to $13.2 \%$ in controls and when at Diane $H$. [48], this rate had reached $77 \%$ among adolescent girls compared to $47 \%$ among controls. The pelvis was normal in the majority of cases, $89.33 \%$ among adolescents compared to $93.33 \%$ among controls. The difference was not statistically significant (p-0.08; OR-0.56). In the literature, the rate of normal pool varies between $92.18 \%$ and $95.7 \%$ among adolescent girls and between $94.06 \%$ and $96.3 \%$ among controls [18] [20] [26]. The generally narrowed pelvis was found in $2 \%$ of adolescent girls compared to $0.33 \%$ of controls with a statistically significant difference $(P=0.05 ; \mathrm{GOLD}=6)$. Gandonou M. [49] had found similar results in adolescent girls in Benin, with $2 \%$ of the pelvis generally narrowed; Drabo A. [26] reported a generally reduced pelvis rate of $4.3 \%$ in adolescent girls (including 4 cases of immature pelvis) and $3.7 \%$ in controls. This may be due to the fact that teenage girls have not finished their physical growth. Fetal heart noises below 120 beats/mn were detected more in adolescents $6.33 \%$ than $1 \%$ controls with a statistically significant difference $(\mathrm{P}=$ 0.0005; OR = 6.7). Drabo A. [26] had reported 3.6\% of adolescent girls with fetal heart noises below 120 beat/mn. The presentation of the summit was the most represented with frequencies of $92.67 \%$ for cases compared to $91.33 \%$ for controls $(\mathrm{P}=0.65$; $\mathrm{OR}=1.2)$. In the literature, the rate of cephalic presentation ranges from $92.18 \%$ to $98.5 \%$ among adolescent girls and from $94.06 \%$ to $98.3 \%$ among controls [18] [20] [22] [26] [44]. The high rate of presentation of the summit could be explained by compliance with the law of accommodation among the majority of our pregnant women.

\subsubsection{The Mode of Delivery and Caesarean Section Indications}

Natural births accounted for $82.33 \%$ for adolescent girls compared to $84.33 \%$ for 
controls $(\mathrm{P}=0.5 ; \mathrm{OR}=0.87)$. In the literature, the rate of vaginal delivery among adolescent girls ranges from $75.9 \%$ to $94.8 \%$ [18] [31] [43]. Instrumental extraction in adolescent girls ranges from $8.4 \%$ to $26.9 \%$, the main indication of which is poor maternal co-operation during the expulsive phase, linked to defective psychological preparation of adolescent girls for safe delivery [19] [50]. In our series, instrumental suction cup extraction was $20.65 \%$ of cases compared to $8.3 \%$ for controls $(\mathrm{P}=0.00008, \mathrm{OR}=2.87)$. Mr. Laghzaoui Boukaidi et al. [51] had found in Morocco that instrumental delivery was $20.25 \%$ among adolescent girls. However, we can say that in the vast majority of cases, teenage delivery is done naturally, as evidenced by these different results. These deliveries required rigorous monitoring of the labour of delivery using the partogram. We recorded $17.67 \%$ of caesarean delivery cases among adolescents compared to $15.67 \%$ of controls $(\mathrm{P}=0.5, \mathrm{OR}=1.1)$. Dembélé $\mathrm{F}$. [18] had found $16.15 \%$ of cases of high-birth among adolescent girls. Sanogo M. [20] had reported a rate of $13.75 \%$ of caesarean adolescent girls for different indications, this rate was $15.78 \%$ according to Yattassaye A. [4] and 5.2\% according to Traoré F. [31], Niane M. [52] and Ongoiba A. [14] reported $24.1 \%$ and $20.04 \%$ of caesarean sections in adolescents, respectively.

\subsection{Cesarean Section Indications}

Adolescent girls are 3 and $1 / 2$ times more likely to have caesarean section for mechanical dystocia, or $49.05 \%$ compared to $21.28 \%$ for controls; with a statistically significant difference (p-0.0039; OR-3.5). Bone growth in women does not end until the age of 18 and the deportation canal does not mature until the age of 20 to 21, although the bone age varies significantly from woman to woman and from population to population depending on nutritional level [2]. In this area, most authors agree that there is an increased risk related to age, and that physical immaturity increases the risk of dystocia, the latter potentially leading to maternal death, as well as serious obstetric complications [2] [7] [9] [53] [54]. Hamada et al. [28] in Rabat, Morocco, reported 57\% of mechanical dystocies as causes of caesarean section in adolescents compared to $20 \%$ in controls.

\subsection{Maternal and Fetal Prognosis}

According to some authors, the association between adolescence birth and adverse maternal and perinatal prognosis could be explained in part by the deleterious social environment [39]. In our series, the majority of participants gave birth without complications, $89.5 \%$ among adolescent girls compared to $95.26 \%$ among controls; the difference was statistically significant $(\mathrm{P}=0.015 ; \mathrm{OR}=0.4)$. Dembélé S. [19] reported $85.8 \%$ of adolescent girls compared to $97.3 \%$ of controls with uncomplicated delivery. A significant number of perineal tears were observed in adolescent girls, at $6.8 \%$ compared to $2.37 \%$ for controls with a statistically significant difference $(P=0.016 ; O R=3.05)$. Dembélé $F$. [18] and Dembélé S. [19] reported $2.08 \%$ and $7.5 \%$ of perineal tears in adolescent girls, 
respectively. This high rate of perineal tears in adolescents compared to adults is dû in part to the immaturity of perineal musculature in adolescent girls. Maternal deaths: We recorded 2 cases of maternal death among adolescent girls or $0.67 \%$ compared to 1 case in controls or $0.34 \%$. The difference was statistically significant (p-0.58; OR-1.95).

Newborn weight: In our series, low birth weight (p-lt; $2500 \mathrm{~g}$ ) was twice as common in adolescents $13.33 \%$ as in controls $6.33 \%$ (p-0.0039; OR-2.2). Traoré F. [31] and Diallo D. [55] reported $13.5 \%$ and $11.8 \%$ of low birth weight respectively among newborns from adolescent mothers. As for Dembélé F. [18], the low birth weight rate was $10.26 \%$ among adolescent girls versus $5.41 \%$ for controls.

Low birth weight may be either preterm infants who are at gestational age or hypotrophy whose weight is less than gestational age. This low birth weight is detrimental to these newborns whose survival depends on rigorous follow-up by the family and health workers. In addition, the results of the multi-variety study conducted by Forum et al. [56] do not show a significant association between maternal age and delivery of a small-weight newborn.

Status of newborns at birth: Thee recorded perinatal deaths were 58.82\% stillborn fresh; $17.65 \%$ stillborn macerated; $23.53 \%$ early neonatal deaths in cases versus $42.11 \%$ of fresh stillbirths; $47.37 \%$ stillborn macerated; $10.52 \%$ of early neonatal deaths among controls. Dembélé F. [18] reported 3.08\% of perinatal deaths among adolescent girls and $2.28 \%$ of perinatal deaths among controls and when at Dembélé S. [19], the perinatal mortality rate was 5.2\% among adolescent girls and $8.8 \%$ among controls. Perinatal mortality varies in the literature between $1.36 \%$ for Konje [57] and 5.4\% for Ryan [54].

\subsection{The Reference Patterns of Newborns in Neonatology}

In our series, $22.33 \%$ of newborns from teenage mothers were referred to neonatology compared to $12.67 \%$ of infants from controls with a statistically significant difference $(\mathrm{P}=0.002 ; \mathrm{OR}=1.98)$. The reasons for evacuation were mainly: Neonatal suffering with $38.81 \%$ among adolescent girls versus $31.58 \%$ among controls; hypotrophy with $20.89 \%$ in adolescent girls versus $26.31 \%$ in controls; prematurity with $32.84 \%$ among adolescent girls versus $23.68 \%$ among controls; fetal macrosomia with $4.48 \%$ in adolescents versus $15.78 \%$ in controls and fetal malformations with $2.98 \%$ in adolescents versus $2.63 \%$ in controls. Dembélé F. [18] found that newborns were referred to paediatrics in $18.97 \%$ of adolescent cases and $11.18 \%$ in controls and Maiga R. [58] reported that the baseline rate for newborns was $15.9 \%$ for adolescent girls and $9.0 \%$ for controls.

\subsection{Pathologies of Diaper Suites}

In the literature, no particular complications of diapers are reported in young mothers [33] [59]. In our study, postpartum anemias, postpartum eclampsia, endometritis were found to be more common in adolescent girls than in con- 
trols: $3.3 \%$ vs. $2 \%, 1.33 \%$ vs. $1 \%, 2.67 \%$ vs. $0.67 \%$ without a statistical link. The P values were $\mathrm{P}=0.3$, respectively; $\mathrm{P}=0.7 ; 0.06$.

\section{Conclusion}

Teenage versus adult births are associated with many more maternal-fetal complications.

\section{Authors' Contributions}

All the authors participated in the writing of the manuscript. They all approve the final version of the manuscript.

\section{Ethics Authorisation}

The ethics committee's authorization was found prior to the start of the study.

\section{Conflicts of Interest}

The authors declare no conflicts of interest regarding the publication of this paper.

\section{References}

[1] Dadoorian, D. (2003) Teenage Pregnancy. Eres Editions, Ramonville-Saint-Agne, $136 \mathrm{p}$.

[2] World Health Organization (1998) World Health Day: Safe Motherhood: Delaying Births. Geneva, 1-3.

[3] Barabara, S. (1996) Family Planning Saves Lives: Teenage Girls and Reproductive Health. 15-18.

[4] Yattasaye, A. (1998) Teenage Giving Birth at the Maternity Ward of CHU. Thesis, Gabriel Touré Medical, Bamako, No. 74, 83 p.

[5] Samaké, S., Traoré, S.M., Ba, S., Dembélé, E., Diop, M., Mariko, S., et al. (2007) Mali Demographic and Health Survey. 410 p.

[6] Eure, C.R., Lindsay, M.K. and Graves, W.L. (2002) Risk of Adverse Pregnancy Outcomes in Young Adolescent Parturients in an Inner-City Hospital. American Journal of Obstetrics and Gynecology, 186, 918-920.

https://doi.org/10.1067/mob.2002.123986

[7] Gallais, A., Robbillard, P.Y., Nuissier, E., Cuitassier, T. and Janky, E. (1996) Adolescence and Maternity in Guadeloupe: About 184 Observations. Journal of Obstetrics and Gynecology and Reproductive Biology, 25, 523-527.

[8] Creatsas, G., Michalas, S., Terzakis, E. and Kaskarelis, D. (1980) Teenage Pregnancy. Gynecology, 31, 343-345.

[9] Carles, G., Jacquelin, X., Raynal, P., Bertsch, M. and Zoccarato, A.M. (1998) Pregnancy and Childbirth in Adolescent Girls under 16 Years of Age. Study of 150 Cases in French Guiana. Journal of Obstetrics and Reproductive Biology, 27, 508-513.

[10] Robin, G. and Letombe, B. (2006) Contraception in the Adolescent Age. 30th National Days of the French National College of Gynaecologists and Obstetricians. Paris, 5-40.

[11] ANRS, INSERM, INED (2007) First Results of the Survey: Background of Sexuality 
in France. Press Kit. March 13, 9-10.

[12] National Institute of Statistics (INSTAT/MPATP); INFO-STAT; ICF International. Demographic and Health Survey in Mali 2012-2013. 577 p.

[13] McIntyre, P. and World Health Organization (2007) Pregnant Teenagers: Bringing Global Promises of Hope. 30 p.

[14] Ongoiba, A. (1999) Teenage Pregnancy and Childbirth at the Hospital of Point G. Thesis of Medicine, Bamako, No. 60.

[15] World Health Organization (2004) Adolescent Pregnancy (Issues in Adolescent Health and Development). WHO, Geneva.

[16] The Van, C. (1998) Teen Pregnancy: Social Norms, Lived Realities. Harmattan, Paris, $206 \mathrm{p}$.

[17] N'diaye, P., Diallo, I. and Fall, C. (2001) A New Decision-Making Tool in the Fight against Maternal Mortality. The Dystocial Risk Score. Health, 11, 133-138.

[18] Dembélé, F. (2015) Teenage Delivery at the Reference Health Centre in Commune IV in Bamako District. Thesis Medicine, No. 80.

[19] Dembélé, S. (2012) Adolescent Childbirth at the Dioila Reference Health Centre. Thesis Med. Bamako, No. 211.

[20] Sanogo, M. (2009) Teenage Delivery at the Reference Health Centre in Commune VI of Bamako District. Thesis Medicine, No. 287.

[21] Fatton, B. (2005) Dynamic Anatomy of the Perineum. In Pelvi-Perineology, 21-30.

[22] Merger, R., Jean, L., Jean, M. and Nelly, B. (2008) Obstetrics. 6th Edition, Masson, Paris, $597 \mathrm{p}$.

[23] Daguerre, A. (2010) Teenage Pregnancies in France and Great Britain: A Disturbing Phenomenon for the Public Authorities. Social Information, 157, 96-102.

[24] Chamaki, A. (1992) Physiology of Puberty. 3rd National Course of School and University Medicine in Tunis. 11: 124.

[25] Coulibaly, B. (1992) Study of Teenage Gravity at the Maternity Ward of the National Hospital of Point "G". Thesis Medicine, Bamako, No. 56.

[26] Drabo, A. (2015) Teenage Pregnancy and Childbirth at the Health Centre Municipality II of Bamako District. Thesis Medicine, Bamako, No. 85.

[27] Population Reference Office (2013) The World Youth Data Sheet. 4 p.

[28] Zuber, M.C. and Blondel, B. (1987) Marital Status, Cohabitation and Pregnancy. Evolution of the Social and Medical Aspects of Out-of-Marriage Births in France. Population, 42, 741-746. https://doi.org/10.2307/1533006

[29] Boisselier, P.H. (1985) Teenage Pregnancy. French Journal of Obstetrics and Biological Reproductive Gynecology, 14, 607-611.

[30] Daguerre, A. (2010) Teenage Pregnancies in France and Great Britain: A Disturbing Phenomenon for the Public.

[31] Traoré, F. (2002) Consequence of Early Pregnancy in the Peri-Urban Area of Bamako. Thesis Medicine, No. 103.

[32] Nekam, F. (1995) Risk Factors for Pregnancy in Single Adolescents in Commune IV. Medical Thesis, Bamako, No. 39.

[33] Hamada, H., Zaki, A., Nejjar, H., Filali, A., Chraibi, C., Bezad, R., et al. (2004) Teenage Pregnancy and Childbirth in Rabat, Morocco: Characteristics and Profile. Journal of Obstetrics and Reproductive Biology, 33, 60714. https://doi.org/10.1016/S0368-2315(04)96601-X 
[34] The Alan Guttmacher Institute (1998) Into a New World: Young Women's Sexual and Reproductive Lives.

[35] Janky, L.S., Gallais, A. and Landre, M. (1996) Generalities on Pregnancy and Childbirth in Adolescent Girls. Medical and Surgical Encyclopedia (Elsevier, Paris) Gynecology-Obstetrics, 5016-D10, 6 p.

[36] Diallo, A. (2013) Adolescent Birth at the Reference Health Centre of Commune VI. Thesis Med. Bamako, No. 146.

[37] Traore, B. (2010) Teenage Giving-Up at the Maternity Ward of the Ségou Regional Hospital Centre. Médecine d Afrique Noire, 57, 449-454.

https://doi.org/10.1353/dss.0.0142

[38] Chaibva, C.N., Ehlers, V.J. and Roos, J.H. (2009) Midwives' Perceptions about Adolescents' Utilisation of Public Prenatal Services in Bulawayo, Zimbabwe. Midwivery, 26, e16-e20.

[39] Markovitz, B.P., Cook, R., Flick, L.H. and Leet, T.L. (2005) Socioeconomic Factors and Adolescent Pregnancy Outcomes: Distinctions between Neonatal and Post-Neonatal Deaths. BMC Public Health, 25, 79. https://doi.org/10.1186/1471-2458-5-79

[40] Suraiya, S.K., Al Sibai, M.H. and AL-Suleiman, S.A. (1986) Obstetric Implications of Pregnancy in Adolescence. Acta Obstetricia et Gynecologica Scandinavica, 65, 57-61. https://doi.org/10.3109/00016348609158231

[41] Reynold, H., Wrigth, K., Olukoya, A. and Neelofur-kan, D. (2004) Adolescent Maternal Care Optic Young. Reproductive Health and HIV/AIDS Serial Publication, 11, 1-4.

[42] Impact Boarding School (1997) Obstetric Gynecology (2) Med. Forensic-Toxicology, Paris, Publisher SA, March No. 18, Chapter 158, 6.

[43] Soula, O., Carles, G., Largeaud, M., El Guindi, W. and Montoya, Y. (2006) Teenage Pregnancy under 15 Years Study of 181 Cases in French Guiana. Journal de Gynécologie Obstétrique et Biologie de la Reproduction, 35, 53-61. https://doi.org/10.1016/S0368-2315(06)76372-4

[44] Benene, A., Elbernoussi, L., Elfarouqi, A., Chraibi, C. and Alaoui, M.T. (2009) Adolescent Childbirth, Oranger Maternity Experience (Rabat, Morocco). About 129 Cases. Maghreb Medicine, Electronic Edition, Number 165, 50-54.

[45] Djanhan, Y., Kodjo, R., Gondo, D., Abauleth, Y.R. and Bohoussou, K.M. (1995) Adolescent Birth at the Chu in Coccody-Abidjan. Black African Medecine, 42, 217-219.

[46] Iloki, L.H., Koubaka, R., Itoua, C. and Mbemba Moutounou, G.M. (2004) Pregnancy and Teen Birth in Congo: About 276 Cases at the Brazzaville University Hospital. Journal of Obstetrics and Reproductive Biology, 33, 37-42. https://doi.org/10.1016/S0368-2315(04)96310-7

[47] Faucher, Ph., Dappe, S. and Madelenat, P. (2002) Maternity in Adolescence: Obstetrical Analysis and Review of the Influence of Cultural, Socioeconomic and Psychological Factors in a Retrospective Study of 62 Cases. Gynecologie, Obstétrique \& Fertilité, 30, 944-952. https://doi.org/10.1016/S1297-9589(02)00497-6

[48] Diane, H. (2011) Teenage Delivery at the Reference Health Centre in the V Commune of Bamako, Mali. Thesis Medicine, No. 265.

[49] Gandounou, M. (2012) Prognosis of Teen Delivery in the University Clinic of Gynecology and Obstetrics at CNHU-HKM (Benin). Thesis Medicine, Bamako.

[50] Sittner, B., Hudson, D.B., Grossman, C. and Gaston-Johansson, F. (1998) Adolescents Perceptions of Pain during Labor. Clinical Nursing Research, 7, 82-93. 
https://doi.org/10.1177/105477389800700107

[51] Laghzaoui, B., Bouhya, S., Bennani, O., Hermas, S., Soummani, A. and Aderdour, M. (2002) Teenage Pregnancy and Childbirth. Morocco Medical, 24, 181-185.

[52] Niane, M. (2000) Adolescent Pregnancy Epidemic Approach at Fousseini DAOU Regional Hospital in Kayes. Thesis Medicine, Bamako, No. 99, 47 p.

[53] Tambwe, M.N.K., Kalenga, M.K. and Kakoma, S.Z. (1999) Teenage Partnering at University Clinics in Lubumbashi, Congo. French Journal of Gynecology and $\mathrm{Ob}$ stetrics, 94, 379-383.

[54] Osbourne, G.K., Howat, R.L. and Jordan, M.M. (1981) The Obstetric Outcome of Teenage Pregnancy. BJOG: An International Journal of Obstetrics \& Gynaecology, 88, 215-221. https://doi.org/10.1111/j.1471-0528.1981.tb00971.x

[55] Diallo, D. (1995) Teenage Delivery in Suburban Settings. Thesis Med. Bamako, No. 48.

[56] Fourn, L., Slobodan, D. and Louise, S. (1999) Factors Associated with the Birth of Low-Weight Children: A Multi-Varied Analysis. French-Language Study and Research Papers/ Health, 9, 7-11.

[57] Konje, J.C., Alan, P., Alan, W., Douglas, M.H., Alastair, I., et al. (1992) Early Teenage Pregnancies in Hull. BJOG: An International Journal of Obstetrics \& Gynaecology, 99, 969-973. https://doi.org/10.1111/j.1471-0528.1992.tb13699.x

[58] Maiga, R. (2010) Adolescent Delivery at Sominè Dolo Hospital in Mopti, Case-Control Study. Thesis Medicine, No. 253.

[59] Vinatier, D., Patey Savatier, P. and Monnier, J.C. (1987) Generalities on Pregnancy and Childbirth in Adolescent Girls. Medical and Surgical Encyclopedia (Paris) Gynecology-Obstetrics, 5016-D10, 165-169. 